\title{
Protective Effect of Piper nigrum on Sodium Arsenite Induced Toxicity in Charles Foster Rats
}

\author{
Shreya Parmar ${ }^{1}$, Arun Kumar, ${ }^{2, *}$ Rudra Pratap Singh Chauhan ${ }^{1}$ \\ ${ }^{1}$ Department of Biochemistry, Magadh University, India \\ ${ }^{2}$ Mahavir Cancer Sansthan and Research Centre, India
}

Received October 1, 2019; Revised July 6, 2020; Accepted July 20, 2020

Copyright $@ 2020$ by authors, all rights reserved. Authors agree that this article remains permanently open access under the terms of the Creative Commons Attribution License 4.0 International License

\begin{abstract}
Arsenic in the present times has caused lots of health hazards to humans. In developing countries like Bangladesh and India the high prevalence of contamination, the isolation and poverty of the rural population, and the high cost and complexity of arsenic removal systems have imposed a programmatic and policy challenge on an unprecedented scale. Although in India, arsenic poisoning in ground water in Gangetic belt especially the districts adjoining the river Ganges right from Eastern Uttar Pradesh, Bihar to West Bengal. These regions are the problem of concern as due to which major health related problems are arising. To combat the present problem, a pre-clinical study was carried out on Charles foster rats. They were treated with Sodium arsenite at the dose of $8 \mathrm{mg}$ per kg body weight for 16 weeks to make arsenic model and upon these arsenic pre-treated rats seed extracts of Piper nigrum at the dose of $50 \mathrm{mg}$ per kg body weight was administered for 4 weeks to study the antidote effects of this plant extract. The Piper nigrum extract not only eliminated the effects of arsenic but also reversed the normal physiological activity in the animal by normalising the activity of liver and kidney. The present study concludes that this novel plant extract possesses hepato-protective as well as nephro-protective activity against arsenic induced toxicity.
\end{abstract}

Keywords Sodium Arsenite, Piper nigrum, Antidote Effects, Charles Foster Rats

\section{Introduction}

Arsenic menace in the entire world has caused serious health hazards to the exposed population. About 300 million population in the entire world is affected with the arsenic poisoning (Hassan 2018). Due to geogenic changes in the Ganga Meghna Brahmaputra basin the arsenic contamination in groundwater has increased many folds (Saha 2009). In Bihar about 10 million population are affected in the entire Gangetic plains of the state (Singh et al., 2014; Kumar et al., 2019). Trivalent arsenic species are the most toxic than pentavalent arsenic compounds. Exposure to arsenic has become a common problem throughout the world due to contaminated drinking water, food and air. Millions of people are worldwide at the risk of many serious diseases of chronic arsenic exposure (US National Research Council, 2001; Kenneth and Gilbert, 2002). Once ingested soluble forms of arsenic are readily absorbed from the gastrointestinal tract to blood stream then distributed to the organs and tissues after first passing through the liver. Generally, arsenic interferes organ and body functions such as the central nervous system (Vahidnia et al., 2008), liver, kidneys (Smith et al., 1998; Kannan et al., 2001) and endocrine, cardiovascular system besides inhibiting DNA repair capability (Hartwig et al., 2002; Andrew et al., 2006) and causing carcinogenic effects on skin, lungs, urinary bladder and kidney. Arsenic toxicity results from its ability to interact with sulfhydryl groups of enzymes and disrupt enzymes involved in cellular respiration, that leads to inhibition of glycolysis and Krebs cycle and substitute phosphorus in a variety of biochemical reactions (Patlolla et al., 2005). The problem of arsenicosis becomes very serious due to its exposure in a larger population and the absence of effective treatments. Thus, the use of pharmacological agents and nutritional supplementation approach to this problem form an attentive possibility. Studies have suggested that nutritious diet could be useful in reducing the risk of arsenic toxicity through their antioxidant activity and also by increasing the methylation of arsenic (Maurya et al., 2011). Recently, phyto-constituents and secondary metabolites from plant source are being explored by many pharmaceutical industries to explore new drugs or dietary supplements. One such potential plant source is seed extracts of Piper nigrum. The phytochemical investigations of $P$. nigrum has 
revealed that it contains variety of phytochemicals. Piperine was the first pharmacologically active compound isolated from different members of Piperaceae family. Many investigators isolated different types of compounds viz Phenolics, flavonoids, alkaloids, amides and steroids, lignans, neolignans, terpenes, chalcones etc. and many other compounds. P.nigrum possesses potential hepato-protective activity due to the presence of piperine alkaloids and have great therapeutic potential in treatment of liver ailments (Nirwane and Bapat 2012 and Damanhouri and Ahmad 2014).

Thus, the present study was undertaken to evaluate the antidote and antitoxic potential of the ethonolic extract of P.nigrum seeds on sodium arsenite induced hepatotoxicity and nephrotoxicity in rats.

\section{Materials and Methods}

Animals and diets: Adult and healthy male Charles Foster strain rats (24) of 8 weeks old weighing around $160 \mathrm{~g}$ to $180 \mathrm{~g}$ were used in the present study. The animals were procured from the animal house of Mahavir Cancer Sansthan and Research Centre, Patna, India (CPCSEA Reg-No. 1129/bc/07/CPCSEA). The experiment was performed after the permission granted by the Institutional Animal Ethics Committee (IAEC) with IAEC No. 2018/1E-10/08/18. The rats were acclimatized in laboratory housing conditions under $12 \mathrm{~h}$ light and dark cycles (room temperature maintain at $22 \pm 2^{\circ} \mathrm{C}$ ) for 15 days prior to the beginning of the treatment under standard laboratory conditions. These experimental rats were housed in conventional polypropylene cages and stainless-steel grill top and offered the diet including food (self-prepared laboratory) and water to rats were provided ad libitum.

Chemical: Arsenic was used as Sodium Arsenite (98.5\%) manufactured by Sigma-Aldrich, USA (CAS Number: 7784-46-5; S7400-100G), Lot\# SLBH5736V, PCode 1001683292, and was purchased from the Scientific store of Patna, Bihar, India.

Preparation of Piper nigrum seeds ethanolic extract: In present study Piper nigrum plant seeds (black pepper) were purchased from local market of Patna, Bihar and identified by Dr. Ramakant Pandey (Botanist), Department of Biochemistry, Patna University, Patna, Bihar, India. The plant seeds washed through running tab water and incubated at $37^{\circ} \mathrm{C}$ temperature then dried seeds grinded to fine powder which was further soaked in $100 \%$ ethanol for 48 hours, and finally extracted using Rota Vapour apparatus after continuous drying for 4 hours at pressure 4 psi. The ethanolic extract dose was calculated after $\mathrm{LD}_{50}$ estimation and the final dose was titrated to $50 \mathrm{mg} / \mathrm{kg}$ body weight. For $\mathrm{LD}_{50}$ estimation, 8 groups of rats $(\mathrm{n}=4$ each) were set up and different doses of plant extract were orally administered for 7 days. The $\mathrm{LD}_{50}$ dose was found to be
4800mg/Kg body weight.

Experimental Design: Rats were randomly divided into four groups, each group containing six rats and categorized as following. Group I: Normal control group. Group II: Arsenic treated- Rats were orally sodium arsenite induced $(8 \mathrm{mg} / \mathrm{kg}$ body weight/day) for 16 weeks and were sacrificed after the completion of the experiment. Group III: Arsenic treated control- Rats were orally treated with sodium arsenite induced ( $8 \mathrm{mg} / \mathrm{kg}$ body weight/day) for 16 weeks and left without any dosing for further 4 weeks. Group IV: Piper nigrum administration- Rats were pretreated with sodium arsenite $(8 \mathrm{mg} / \mathrm{kg}$ body weight/day) followed by administration of Piper nigrum ethanolic seed extract (50mg/kg body weight/day) for 4 weeks. After the end of dosing, rats were anaesthetized by diethyl ether and sacrificed. Blood samples were collected through the orbital puncture from all groups. Serum was separated for the various biochemical estimation.

Histopathological study: For histopathology examination, liver and kidney tissues collected from all the groups of rats, and washed in normal saline then grossed in to small pieces and fixed into $10 \%$ formalin for 24 hours. There after further dehydration process through series of ethanol and tissue embedding into paraffin. Sections were cut at $5 \mu \mathrm{m}$ thickness through microtome and stained with hematoxylin and eosin (H\&E) for the investigation of histopathological changes under light microscope.

Biochemical assay: Biochemical analysis were performed through the serum by standard kit process (Coral crest) through (UV - Vis) spectrophotometer (UV-10, Thermo Fisher, USA). The Liver Function Test as Serum Glutamic Pyruvate Transaminase (SGPT) and Serum Glutamic Oxaloacetate Transaminase (SGOT) were measured according to the method (Reitman \& Frankel, 1957), Alkaline Phosphate (ALP) by method (Kind \& King, 1954), total bilirubin activity by method (Jendrassik \& Grof, 1983) while albumin level measured by BCG method. The Kidney Function Test (KFT) were analysed through Urea by (Fawcett, 1960 and Berthelot, 1859), Creatinine by (Toro, et al 1975), and Uric acid by (Bones, 1945).

Lipid Peroxidation (LPO): Thiobarbituric acid reactive substances (TBARS), as a marker of LPO, were evaluated through the double heating method (Draper and Hadley, 1992) based on the principle of spectrophotometric measurement of color reproduced during the reaction to thiobarbituric acid (TBA) with malondialdehyde (MDA). For this study, $2.5 \mathrm{ml}$ of $100 \mathrm{gm} / \mathrm{L}$ solution of Trichloroacetic acid (TCA) was mixed with $0.5 \mathrm{ml}$ serum in a centrifuge tube and heated in the water bath at $90^{\circ} \mathrm{C}$ for 15 minutes. After cooling at room temperature, the mixture was further centrifuged at $3000 \mathrm{rpm}$ for 10 minutes, and $2 \mathrm{ml}$ of the supernatant was mixed with $1 \mathrm{ml}$ of $6.7 \mathrm{gm} / \mathrm{L}$ TBA solution in a test tube which was further heated in water bath at $90^{\circ} \mathrm{C}$ for 15 minutes and left for cooling at the room temperature. Thereafter. absorbance was measured by UV - Visible spectrophotometer (Thermo Scientific 
UV-10 US A) at $532 \mathrm{~nm}$.

Statistical analysis: Results are presented as mean \pm Standard Deviation (SD) for six rats individual groups and total variation represented in a set of data was analyzed through one-way Analysis of Variance (ANOVA). Differences among mean variance has been analyzed by applying Dunnett's 't' test at $99.9 \%(\mathrm{p}<0.05)$ confidence level. Calculations were performed with the GraphPad Prism Program (GraphPad Software, Inc., San Diego, USA).

\section{Result}

Haematological Study: In the present study, the data of haematological parameters are shown in Table.1, and the study shows significant decrease $(p<0.0001)$ in the erythrocyte counts (RBCs), haemoglobin percentage, haematocrit percentage, MCV, MCH after 16 weeks of exposure but there was significant increase in leukocyte count (WBCs) in comparison with the control group. But, after administration of Piper nigrum there was significant reversal in the haematological values. ANOVA showed that the sodium arsenite has more deleterious effect on time duration of exposure $(\mathrm{p}<0.0001)$.

Table 1. Changes in the haematological parameters of Charles Foster rats exposed to Sodium arsenite at the dose of $8 \mathrm{mg} / \mathrm{Kg}$ body weight daily for 16 weeks and its amelioration by Piper nigrum at the dose of 50 $\mathrm{mg} / \mathrm{Kg}$ body weight for 4 weeks.

\begin{tabular}{lccc}
\hline \multicolumn{1}{c}{ Blood Parameters } & Control & $\begin{array}{c}\text { Arsenic } \\
\text { treated }\end{array}$ & $\begin{array}{c}\text { Piper nigrum } \\
\text { treated }\end{array}$ \\
\hline RBC Counts $\left(10^{6} / \mathrm{mm}^{3}\right)$ & $7.17 \pm 0.16$ & $2.77 \pm 0.12$ & $4.65 \pm 0.23$ \\
Hb (g/L) & $90.8 \pm 1.08$ & $52.42 \pm 0.73$ & $67.1 \pm 2.07$ \\
Haematocrit percentage & $272 \pm 3.08$ & $148 \pm 0.87$ & $190 \pm 3.14$ \\
(Hct) (\%) & $364 \pm 18.6$ & $562 \pm 8.96$ & $497 \pm 6.43$ \\
MCV (fL) & $127 \pm 1.40$ & $202 \pm 1.79$ & $181 \pm 2.01$ \\
MCH (pg) & $33.4 \pm 0.036$ & $31.6 \pm 0.01$ & $32.2 \pm 0.034$ \\
MCHC $(\mathrm{g} / \mathrm{L})$ & $7500 \pm 28.9$ & $15169 \pm 12.3$ & $10221 \pm 7.62$ \\
WBC $\left(10^{3} / \mathrm{mm}^{3}\right)$ & & &
\end{tabular}

*The data are presented as mean $\pm S . D, n=6$, significance at $P<0.0001$.

\section{Biochemical Assay:}

The biochemical assay showed the following findings in control group of rats, SGPT level was $28.33 \pm 2.028$ $\mathrm{U} / \mathrm{ml}$, after 16 weeks of arsenic exposure it was $193.3 \pm$ 18.45 U/ml, while after 4 weeks of Piper nigrum administration it was $58.12 \pm 1.386 \mathrm{U} / \mathrm{ml}$ (Figure 1). In control group of rats, SGOT level was $32.56 \pm 1.21 \mathrm{U} / \mathrm{ml}$, after 16 weeks of arsenic treatment it was $174.10 \pm 2.03$ U/ml, while after 4 weeks of Piper nigrum administration, it was $56.27 \pm 1.216 \mathrm{U} / \mathrm{ml}$ (Figure 2). In control group of rats, ALP level was $7.8 \pm 3.32 \mathrm{~K}$.A units, after 16 weeks of arsenic exposure it was $24.28 \pm 6.45$ K.A units, while after 4 weeks of Piper nigrum administration, it was $12.95 \pm$ 5.318 K.A units (Figure 3). In control group of rats, bilirubin level was $0.8 \pm 1.21 \mathrm{mg} / \mathrm{dl}$, after 16 weeks of arsenic treatment it was $2.49 \pm 3.67 \mathrm{mg} / \mathrm{dl}$, while after 4 weeks of Piper nigrum administration, it was $1.35 \pm 2.86$ $\mathrm{mg} / \mathrm{dl}$ (Figure 4). In control group of rats, the kidney function test urea level was $19.28 \pm 2.67 \mathrm{mg} / \mathrm{dl}$, after 16 weeks of arsenic treatment it was $87.21 \pm 3.95 \mathrm{mg} / \mathrm{dl}$, while after 4 weeks of Piper nigrum administration, it was 39.13 $\pm 3.12 \mathrm{mg} / \mathrm{dl}$ (Figure 5). In control group of rats, uric acid level was $5.10 \pm 0.87 \mathrm{mg} / \mathrm{dl}$, after 16 weeks of arsenic treatment it was $14.56 \pm 0.36 \mathrm{mg} / \mathrm{dl}$, while after 4 weeks of Piper nigrum administration, it was $6.78 \pm 30.30 \mathrm{mg} / \mathrm{dl}$ (Figure 6). In control group of rats, the creatinine level was $0.89 \pm 1.19 \mathrm{mg} \%$, after 16 weeks of arsenic treatment it was $3.9 \pm 1.37 \mathrm{mg} \%$, while after 4 weeks of Piper nigrum administration, it was $1.8 \pm 1.86 \mathrm{mg} \%$ (Figure 7). In control group of rats, the lipid peroxidation level was $1.800 \pm$ $0.1732 \mathrm{nmol} / \mathrm{ml}$, after 16 weeks of arsenic treatment it was $48.33 \pm 1.856 \mathrm{nmol} / \mathrm{ml}$, while after 4 weeks of Piper nigrum administration, it was $17.33 \pm 1.453 \mathrm{nmol} / \mathrm{ml}$ (Figure 8).

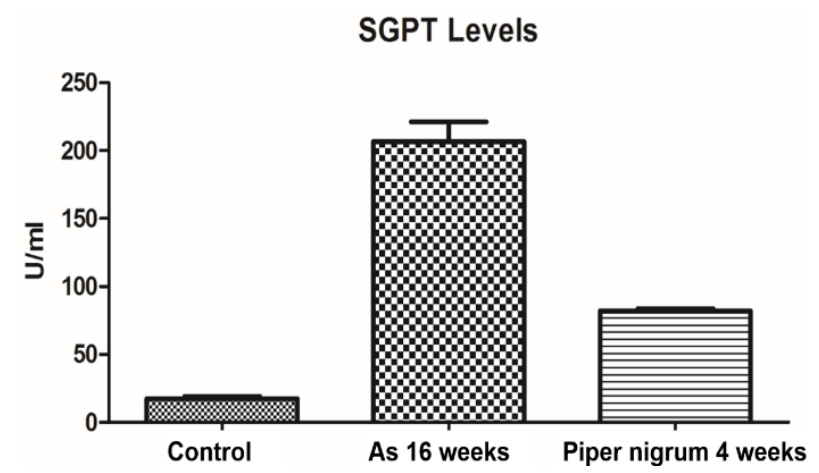

Figure 1. Effect of Piper nigrum on arsenic induced toxicity showing SGPT activity $(\mathrm{n}=6$, values are mean \pm S.D).

\section{SGOT Levels}

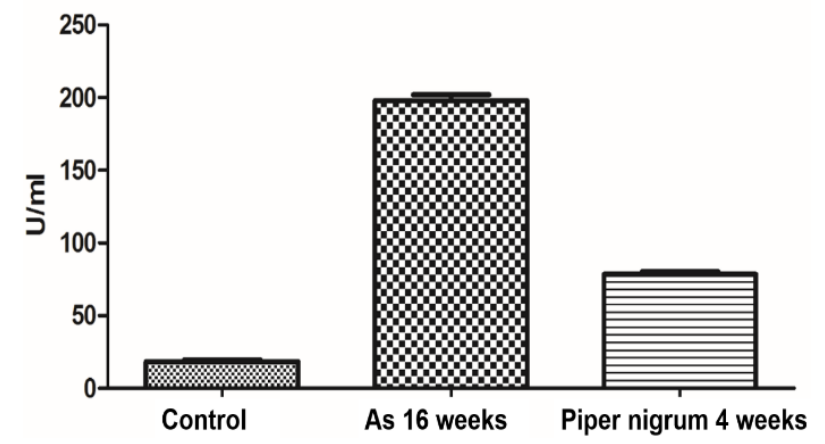

Figure 2. Effect of Piper nigrum on arsenic induced toxicity showing SGOT activity ( $n=6$, values are mean \pm S.D). 


\section{ALP Levels in serum of Rats}

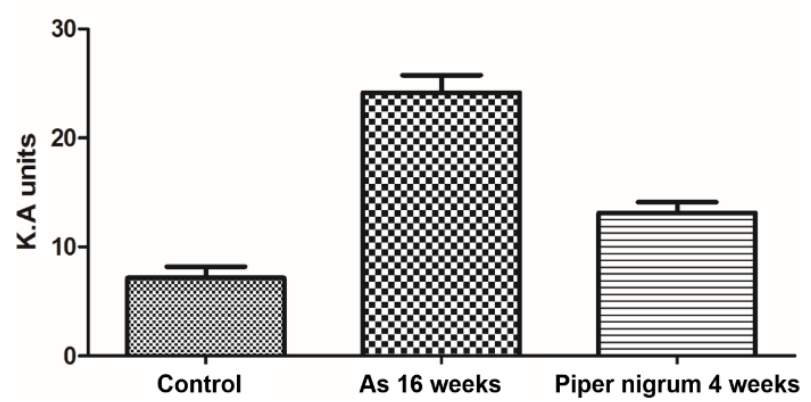

Figure 3. Effect of Piper nigrum on arsenic induced toxicity showing Alkaline Phosphatase activity ( $n=6$, values are mean \pm S.D).

\section{Bilirubin Levels in serum of Rats}

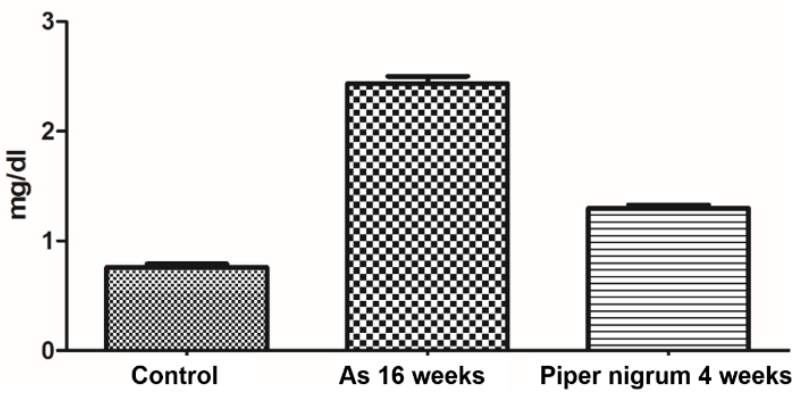

Figure 4. Effect of Piper nigrum on arsenic induced toxicity showing Bilirubin activity ( $\mathrm{n}=6$, values are mean \pm S.D).

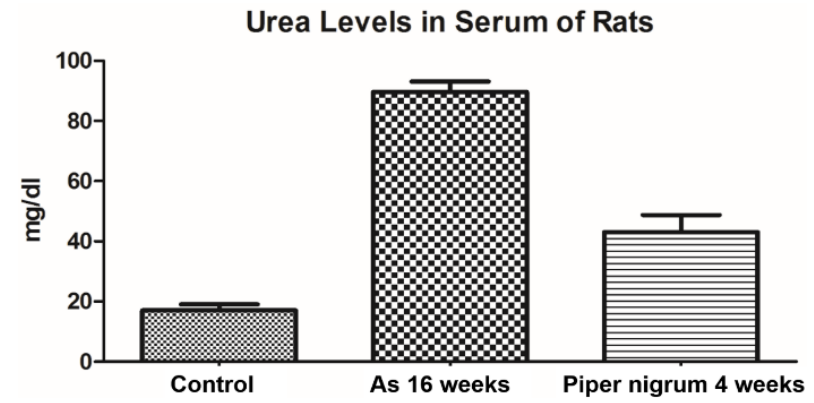

Figure 5. Effect of Piper nigrum on arsenic induced toxicity showing Urea activity $(n=6$, values are mean \pm S.D).

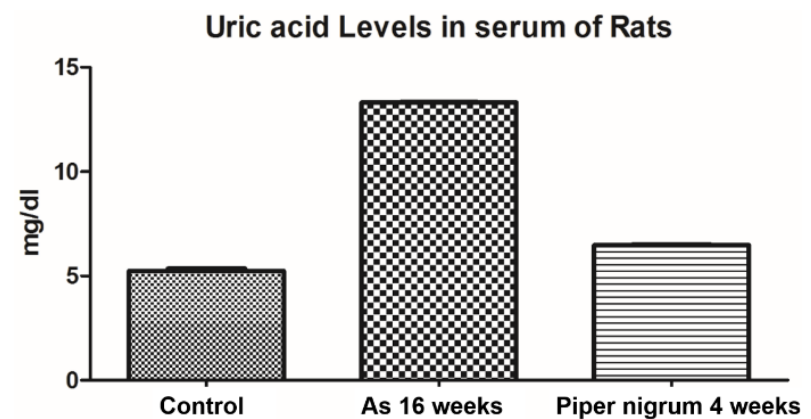

Figure 6. Effect of Piper nigrum on arsenic induced toxicity showing Uric acid activity ( $n=6$, values are mean \pm S.D).

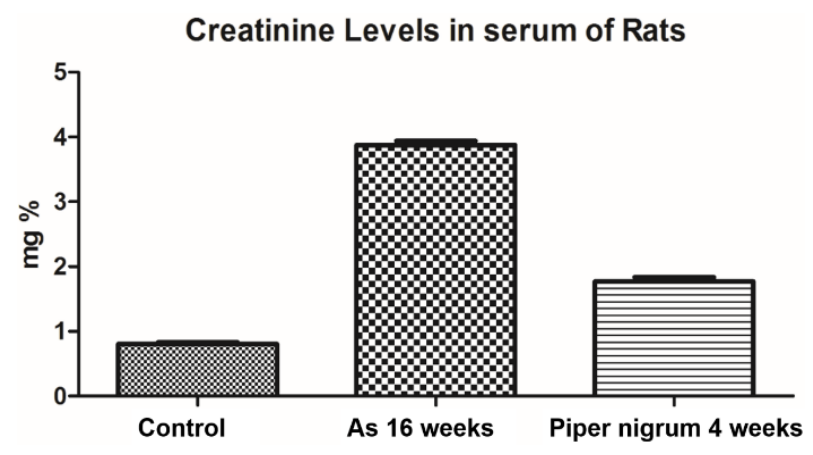

Figure 7. Effect of Piper nigrum on Arsenic induced toxicity showing Creatinine activity ( $\mathrm{n}=6$, values are mean+ S.D).

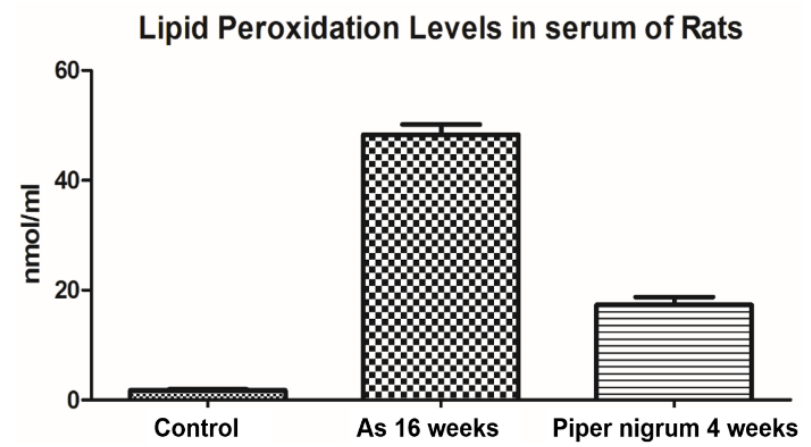

Figure 8. Effect of Piper nigrum on Arsenic induced toxicity showing Malondialdehyde activity (Lipid Peroxidation) ( $\mathrm{n}=6$, values are mean \pm S.D).

Histopathological Study: In the present histopathological study, the liver sections showed normal architecture of hepatocytes, central vein along with sinusoids denotes the normal cellular function in the liver (Figure 9-1A). The arsenic treated group showed very high degree of degeneration in the hepatocytes with haemorrhage in the central vein. The severe vacuolisations in the sinusoids are also visualized (Figure 9-1B). But, after the administration of Piper nigrum, there was significant normalization in the hepatocytes, central vein and sinusoids (Figure 9-1C). The kidney sections showed normal architecture of nephrocytes, Bowman's capsule and glomerulus, convoluted tubules and distal tubules (Figure 9-2A). The arsenic treated group showed degeneration in the nephrocytes with haemorrhage in the glomerulus. Intermingling of two Bowman's capsules is also visualized (Figure 9-2B). But, after the administration of Piper nigrum, there was significant normalization in the nephrocytes, along with the Bowman's capsule and glomerulus, convoluted tubules and distal tubules (Figure 9- 2C). 

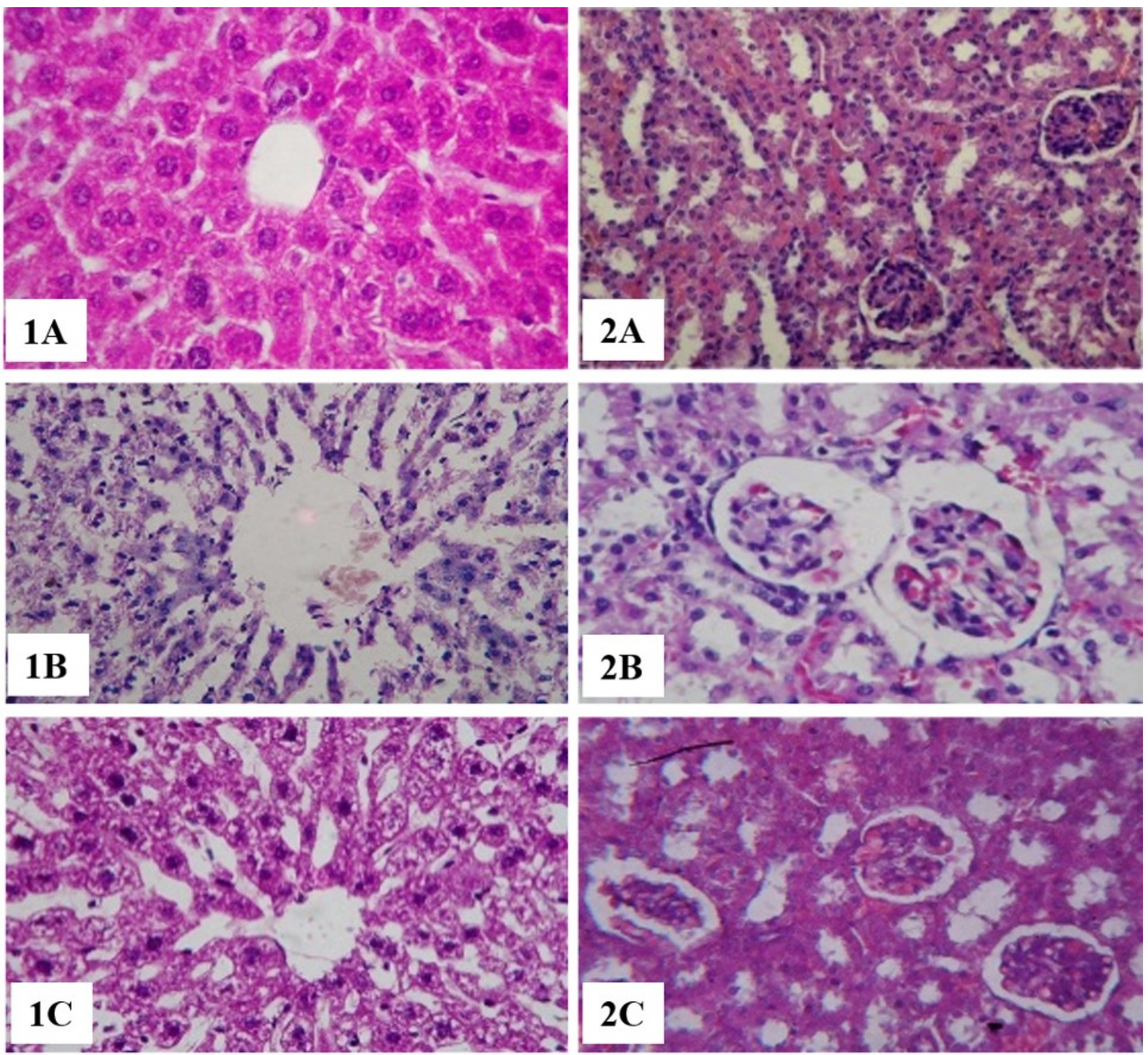

Figure 9. 1A. Microphotographs section of liver tissue of control rat stained with haemotoxylin and eosin showing polygonal hepatocytes with centrally placed nucleus with intact dense cytoplasm. Sinusoids are clearly seen which are opening in the Central Vein X500. 1B. The 16 weeks arsenic treated rats showing degenerated hepatocytes with degenerated nucleus and degenerated cytoplasm. Degeneration in the endothelial cells of the central vein was observed. X500. 1C. After Piper nigrum administered upon 16 weeks arsenic treated rats showed significant amelioration in the hepatocytes as very least degeneration was observed. Granulated nuclei are observed in hepatic cells with only few vacuolated spaces. Sinusoids and central vein are also restored at much extent along with nuclear material. X500. 2A. Microphotographs section of kidney tissue of control rat stained with haemotoxylin and eosin showing normal architecture of nephrocytes, Bowman's capsule, glomerulus. X500 2B. The 16 weeks arsenic treated rats showed degenerated nephrocytes with haemorrhage in the Bowman's capsule, convoluted and distal tubules X500. 2C. After Piper nigrum administered upon 16 weeks arsenic treated rats showed significant amelioration in the nephrocytes. However, mild haemorrhage is still persistent. X500.

\section{Discussion}

Arsenic poisoning in the recent times has caused serious health hazards to the exposed population. The drinking water contamination is the major route cause of exposure in the population. The $\mathrm{As}^{+3}$ is more toxic than $\mathrm{As}^{+5}$ thus makes the probability of arsenite binding to proteins especially the sulfhydryl group. This makes the arsenite's initial increase in the concentration and making the reservoir which releases arsenite for the methylation (Yamanaka, 2004). The methylation of arsenite is catalyzed by a specific methyltransferase using adenosylmethionine as a methyl donating cofactor (SAM). This leads to abnormal metabolic functioning in the cells causing the development of the disease.

In the present study, there was, significant change in the haematological parameters such as decrease in the RBC counts, platelets count, haemoglobin and HCT percentage while there was increase in the WBC counts after the exposure of arsenic in the rats. Similarly, there was significant damage to the biochemical parameters - liver function tests such as SGPT, SGOT, ALP and bilirubin 
levels while in kidney function tests such as urea, uric acid and creatinine levels. The lipid peroxidation levels have also significantly increased denotes the suppression of the defense mechanism system in the cells. The histopathological study also showed very high degree of degeneration in the hepatocytes and nephrocytes due to arsenic toxicity in rats.

Many similar, studies in animals and cell cultures have shown the adverse effects of methylated arsenic, such as $\mathrm{DMA}^{\mathrm{V}}$ as a tumor promoter (Yamamoto et.al, 1995 \& Wanibuchi, et. al, 1996) or direct genotoxic action of $\mathrm{MMA}^{\mathrm{III}}$ and DMA ${ }^{\mathrm{III}}$ in vitro (Cohen, et al. 2006). The main excretion route of arsenic is through the urine and bile. However, the various arsenic metabolites do not excrete in the same fashion in different animals and humans. The most important part is that trivalent arsenic metabolites inhibits pyruvate dehydrogenase (PDH), which leads to disruption of the energy system of the cells (Helleday et. al, 2000) which in turn may release an apoptosis-inducing factor (AIF) resulting in cell damage and death. Inhalation causes lung tumors, while oral exposure causes skin tumors. Individuals chronically consuming arsenic contaminated water also exhibit cancer in other organs including the bladder, liver and kidney (Mallikarjuna et al., 2003; Yamanaka et al. 2004). Since, the liver tends to accumulate arsenic with repeated exposures, hepatic involvement has been reported most commonly as a complication of chronic exposures over periods of months or years. (Soni, et al. 1993). In present study also, we observed the significant increase in the liver function parameters which are associated with the same mechanisms.

Furthermore, there is clear evidence that arsenic disrupts the gene expression, particularly through its effects on signal transduction. Arsenic can interact directly with the glucocorticoid receptor (GR), selectively inhibiting GR-mediated transcription. It has been suggested that arsenic can disrupt cell division by disarranging the spindle apparatus (Miller et. al., 2002), chromosome damage and aneuploidy, and causes micronucleus formation, DNAprotein cross-linking, and sister chromatid exchange (Huang et al., 2004). It is known to inhibit DNA repair and even to exacerbate the effects of other mutagenic agents, thereby increasing susceptibility to multiple diseases (Duker et al.,2005).

Recent epidemiological studies speculate that arsenic is associated with chronic kidney disease which caused reduced glomerular filtration rate, increased urine albumin excretion and this trend is increasing rapidly in arsenic exposed area (Chen et al., 2011; Hsueh et al., 2009; Zheng et al., 2013 \& 2014; Jha et al., 2013). Since, arsenic metabolism is considered for both as a detoxification and bioactivation process. The Dimethyl Arsenic Acid (V) $\left(\mathrm{DMA}^{\mathrm{V}}\right)$ are rapidly excreted in the urine and this makes the proximal tubules of nephrons more vulnerable to the DMA higher concentration than other tissues. This causes high degree of cellular damage to the nephrocytes (Styblo et al., 2002; Carter et al. 2003). In the present study also, there was significant increase in the biochemical levels of kidney function parameters like urea, uric acid and creatinine while the histopathological study also showed cellular damage in the nephrocytes due to arsenic exposure to rats.

In the present study, Piper nigrum was used as antidote against arsenic induced toxicity, which showed significant restoration at the haematological level, biochemical levels especially the SGPT, SGOT, ALP, bilirubin, urea, uric acid, creatinine and lipid peroxidation levels. Moreover, there was marked restoration at the cellular level as there was normalization in cellular functions of hepatocytes as well as the nephrocytes. In the study it was found that piperine inhibited the increased level of serum biomarkers of liver as well as kidney. Piperine increases the absorption of many drugs and nutrients from the gastrointestinal tract by various mechanisms. It alters the membrane dynamics and increases permeability at site of absorption. Piperine increases the serum half-life of some substances like beta-carotene and coenzyme Q10 and decreases metabolism of many drugs by inhibiting various metabolizing enzymes like cytochrome BS, CYP3A4, NADPH cytochrome, UDP-glucuronyl transferase, UDP-glucose dehydrogenase (UDP-GDH), and aryl hydrocarbon hydroxylase (AAH) (Acharya et al., 2012;. Damanhouri and Ahmad 2014). Hence, Piperine possesses potential hepato and renal protective activities against arsenic induced toxicity. Similar studies have found the protective effect of Piper nigrum at biochemical and cellular level in the in vivo models (Singh and Katiyar 2019; Ahmad et al., 2012; Bang et al., 2009; Vijayakumar et al., 2004; Rauscher et al., 2000).

Hence, the present study speculates that Piper nigrum plays the vital role to combat the toxic effects of arsenic at haematological, biochemical and histopathological levels. Similarly, the humans exposed to arsenic have the similar changes and thus Piper nigrum at the titrated dose could prove to be antitoxic drug against arsenic.

\section{Conclusions}

Thus, from the entire study it can be concluded that arsenic causes high degree of degeneration at the haematological, biochemical and histopathological level to the rats disrupting the normal functioning of the body. But, after the administration of the Piper nigrum there was significant restoration in the cells. There was normalization in the functions of the liver and kidney enzymes while the marked cellular normalization denotes the normal physiological activity at the tissue level. Thus, indicates that Piper nigrum possesses hepato-renal protective effect against arsenic induced toxicity. Hence, it can be targeted as novel and safe antitoxic drug against arsenic. 


\section{Acknowledgements}

The authors are thankful to Mahavir Cancer Sansthan and Research Centre for providing infrastructural facility during this work and Department of Biochemistry, Magadh University, Bodh Gaya for the experimental support.

\section{REFERENCES}

[1] Acharya SG, Momin AH and Gajjar AV (2012) Review of Piperine as A Bio-Enhancer. Am J Pharm Tech Res 2:32-44.

[2] Ahmad N, Fazal H, Abbasi BH, Farooq S, Ali M, et al. (2012) Biological role of Piper nigrum L. (Black pepper): A review. Asian Pacific J Trop Biomed: S1945-S1953.

[3] Andrew AS, Burgess JL, Meza MM, Demidenko E, Waugh MG, Hamilton JW, Karagas MR. Arsenic exposure is associated with decreased DNA repair in vitro and in individuals exposed to drinking water arsenic. Environ Health Perspect. 2006 Aug;114(8):1193-8.

[4] Bang, J.S.; Oh, D.H.; Choi, H.M.; Sur, B.J.; Lim, S.J.; Kim, J.Y.; Yang, H.I.; Yoo, M.C.; Hahm, D.H.; Kim, K.S. Anti-inflammatory and antiarthritic effects of piperine in human interleukin $1 \beta$-stimulated fibroblast-like synoviocytes and in rat arthritis models. Arthritis Res. Ther., 2009, 11(2), R49.

[5] Bones RW and Tausky HH. 1945. Colorimetric determination of creatinine by the Jaffe reaction. J. Biol. Chem. 158:581-591

[6] Carter DE, et al. The metabolism of inorganic arsenic oxides, gallium arsenide, and arsine: a toxicochemical review. Toxicol Appl Pharmacol. 2003;193:309-34.

[7] Chen Y, Parvez F, Liu M, et al. Association between arsenic exposure from drinking water and proteinuria: results from the Health Effects of Arsenic Longitudinal Study. Int J Epidemiol. 2011:828-35.

[8] Cohen SM, Arnold LL, Eldan M, Lewis AS, Beck BD. (2006); Methylated arsenicals: the implications of metabolism and carcinogenicity studies in rodents to human risk assessment. Crit. Rev. Toxicol., 36: 99-133.

[9] Damanhouri ZA, Ahmad A (2014) A Review on Therapeutic Potential of Piper nigrum L. (Black Pepper): The King of Spices. Med Aromat Plants 3: 161.

[10] Draper HH, Hadley M. 1990. Malondialdehyde determination as index of lipid peroxidation. Methods Enzymol, 186: 421-431.

[11] Duker AA, Carranza EJM, Hale M (2005). Arsenic geochemistry and health. Environ. Int. 31: 631-641.

[12] Fawcett JK and Scott JE. 1960. A rapid and precise method for the determination of urea. J. Chem. Pathol. 13:156.

[13] Hartwig A, Asmuss M, Ehleben I, Herzer U, Kostelac D, Pelzer A, Schwerdtle T, Bürkle A. Interference by toxic metal ions with DNA repair processes and cell cycle control: molecular mechanisms. Environ Health Perspect. 2002 Oct;110 Suppl 5:797-9.
[14] Hassan M (2018) Arsenic in groundwater. CRC Press, Boca Raton.

[15] Helleday T, Nilsson R, Jenssen D. (2000); Arsenic [III] and heavy metal ions induce intrachromosomal homologous recombination in the hprt gene V79 Chinese hamster cells. Environ. Mol. Mutagen., 35: 114-122.

[16] Hsueh YM, Chung CJ, Shiue HS, et al. Urinary arsenic species and CKD in a Taiwanese population: a case-control study. Am J Kidney Dis. 2009;54:859-70.

[17] Huang C, Ke Q, Costa M, Shi X (2004). Molecular mechanisms of arsenic carcinogenesis. Mol. Cell Biochem. 255: 57-66.

[18] Jendrassik GF and Grofs BM. 1938. Quantitative colorimetric determination of bilirubin in serum or plasma. Clin.Chem. Acta. (27):79.

[19] Jha V, Garcia-Garcia G, Iseki K, et al. Chronic kidney disease: global dimension and perspectives. Lancet. 2013;382:260-72.

[20] Kannan GM, Tripathi N, Dube SN and Flora SJS (2001) Toxic effects of arsenic (III) on some hematopoietic and central nervous system variables in rats and guinea pigs. Journal of Toxicology. Clinical Toxicology 39(7): 675-682.

[21] Kenneth GB, Gilbert LR (2002) Arsenic, drinking water,and health: a position paper of the American council on science and health. Regulatory Toxicology and Phar-macology36(2): 162-174.

[22] Kind PRH and King EJ. 1954. Determination of Alkaline Phosphatase activity in serum. J. Clin. Path. 7: 322.

[23] Kumar A, Ali M, Kumar R, Rahman S. M, Srivastava A, Chayal K. N, Sagar V, Kumari R, et al. 2019. High Arsenic Concentration in Blood Samples of People of Village Gyaspur Mahaji, Patna, Bihar Drinking Arsenic-Contaminated Water. ISSN 2451-9766 Expo Health DOI 10.1007/s12403-018-00294-5.

[24] Mallikarjuna GU, Dhanalakshmi S, Raisuddin S, Rao AR. (2003); Chemomodulatory influence of Ferula assafoetida on mammary epithelial differentiation, hepatic drug metabolizing enzymes, antioxidant profiles and $\mathrm{N}$-methyl-N-nitrosourea-induced mammary carcinogenesis in rats. Breast Cancer Res Treat.;81:1-10.

[25] Maurya, U. and Srivastava, S. 2011. Traditional Indian herbal medicine used as antipyretic, antiulcer, anti-diabetic and anticancer: A review. International Journal of Research in Pharmaceutical Chemistry, 4:1152-9.

[26] Miller, W.H.; Schipper, H.M.; Lee, J.S.; Waxman, S. (2002) Mechanisms of action of arsenic trioxide. Cancer Res., 62: 3893-3903.

[27] Nirwane A M, Bapat A R (2012) Effect of methanolic extract of Piper nigrum fruits in Ethanol-CCl4 induced hepatotoxicity in Wistar rats. Der Pharmacia Lettre 4:795-802.

[28] Patlolla, A.K., Tchounwou, P.B., 2005. Serum acetyl cholinesterase as a biomarker of arsenic induced neurotoxicity in Sprague-Dawley rats. International Journal of Environmental Research and Public Health, 2: 80-83. http://www.mdpi.com/1660- 4601/2/1/80/pdf. 
[29] Rauscher, F.M.; Sanders, R.A.; Watkins, J.B., III Effects of piperine on antioxidant pathways in tissues from normal and streptozotocin induced diabetic rats. J. Biochem. Mol. Toxicol., 2000, 14(6), 329-334.

[30] Reitman's S. and Frankel's S. 1957. A colorimetric method for determination of serum glutamate oxalacetic and glutamic pyruvate transaminases.” Amer J Clin Path1957; 28(1): 56-63.

[31] Saha D. (2009) Arsenic groundwater contamination in parts of middle Ganga plain, Bihar. Current Science. 97(6)753-755.

[32] Singh MK, Katiyar D. Medicinal Impact of Piper- Nigrum (Piperine) Against Arsenic Induced Hepatic and Renal Toxicity in Experimental Mice. Ann. Int. Med. Den. Res. 2019; 5(4):BC01-BC07.

[33] Singh SK, Ghosh AK, Kumar A, Kislay K, Kumar C, Tiwari RR, et al. 2014. Groundwater arsenic contamination and associated health risks in Bihar, India, Int $\mathrm{J}$ Environ Res. 8:49- 60 .

[34] Smith AH, Goycolea M, Haque R and Biggs ML (1998) Marked increase in bladder and lung cancer mortality in a region of northern Chile due to arsenic in drinking water. American Journal of Epidemiology 147(7): 660-669.

[35] Soni KB, Rajan A, Kuttan R. (1993); Inhibition of aflatoxin-induced liver damage in ducklings by food additives. Mycotoxin Res.;9:22-7.

[36] Styblo M, et al. The role of biomethylation in toxicity and carcinogenicity of arsenic: a research update. Environ Health Perspect. 2002;110(Suppl 5):767-71.

[37] Toro,G. etal. (1975) practical clinical chem.. P:154

[38] US NRC (2001) Arsenic in drinking water, 2001 update.
Washington, DC, US National Research Council, National Academy Press.

[39] Vahidnia A, Romijn F, van der Voet GB and de Wolff F A (2008) Arsenic-induced neurotoxicity in relation to toxicokinetics: Effects on sciatic nerve proteins. ChemicoBiological Interactions 176(2-3): 188-195.

[40] Vijayakumar RS, Surya D, Nalini N (2004) Antioxidant efficacy of black pepper(Piper nigrum L.) and piperine in rats with high fat diet induced oxidative stress.

[41] Wanibuchi H, Yamamoto S, Chen H, Yoshida K, Endo G, Hori T, Fukushima S. Promoting effects of dimethylarsinic acid on N-butyl-N-(4-hydroxybutyl)nitrosamine-induced urinary bladder carcinogenesis in rats. Carcinogenesis. 1996;17:2435-2439.

[42] Yamamoto S, Konishi Y, Matsuda T, Murai T, Shibata MA, Matsui-Yuasa I, Otani S, Kuroda K, Endo G, Fukushima S. Cancer induction by an organic arsenic compound, dimethylarsinic acid (cacodylic acid), in F344/DuCrj rats after pretreatment with five carcinogens. Cancer Res. 1995;55:1271-1276.

[43] Yamanaka K, Kato K, Mizoi M, An Y, Takabayashi F, Nakano M, Hoshino M, Okada S. (2004); The role of active arsenic species produced by metabolic reduction of dimethylarsinic acid in genotoxicity and tumorigenesis. Toxicol. Appl. Pharmacol., 198: 385-393.

[44] Zheng L, Kuo CC, Fadrowski J, Agnew J, Weaver VM, Navas-Acien A. Arsenic and Chronic Kidney Disease: A Systematic Review. Curr Environ Health Rep. 2014;1(3):192-207. doi:10.1007/s40572-014-0024-x.

[45] Zheng LY, Umans JG, Tellez-Plaza M, et al. Urine arsenic and prevalent albuminuria: evidence from a population-based study. Am J Kidney Dis. 2013;61:385-94. 